19 Toth $\mathrm{M}$, Witkin S, Ledger $\mathrm{W}$, Thaler $\mathrm{H}$. The role of infection in the etiology of preterm birth. Obstet Gynecol 1988;71:723-6.

20 Naeve RL, Peters EC. Causes and consequences of premature rupture of the membranes. Lancet 1980;: 192-4.

21 Wang E, Smaill F. Infection in pregnancy. In: Chambers I, Enkin M, Keirse MJNC, eds. Effective care in pregnancy and childbirth. Oxford: Oxfor University Press, 1989:534-64

22 Illsley R, Kincaid JC. Social correlations of perinatal mortality. In: Butler NR Bonham DG, eds. Perinatal mortality: the first report of the British perinatal mortality survey. Edinburgh: E and S Livingstone, 1963:270-86.

23 Investigators of the John Hopkins Study of Cervicitis and Adverse Pregnancy Outcome. Associations of Chlamydia trachomatis and Mycoplasma hominis with intrauterine

24 Romero $R$, Sirtori M O Oraun $E$, Avila $C$ Mazor M, Callahan R, at Infection and labor. V. Prevalence, microbiology and clinical significance of intra-amniotic fluid infection in women with preterm labur and intact membranes. Am f Obstet Gynecol 1989:161:817-24.

25 Romero R, Mazor M, Oyarzun E, Sirtori M, Wu YK, Hobbins JC. Is there an association between colonization with group $\mathrm{B}$ streptococcus and prematurity? J Reprod Med 1989;34:797-801.

26 Romero R, Oyarzun E, Mazor M, Sirtori M, Hobbins JC, Bracken M. Metaanalysis of the relationship between asymptomatic bacteriuria and preterm delivery/low birthweight. Obstet Gynecol 1989;73:576-82.

27 Lee MLF. Infections and prematurity: Is there a relationship? fournal of Perinatal and Neonatal Nursing 1988;2:10-20.

28 McGregor JA, French JL, Lawellin D, Todd JK. Preterm birth and infection: pathogenic possibilities. Am F Reprod Immunol Microbiol 1988;16 $123-32$

(Accepted 30 August 1991)

\title{
Risk of epilepsy after febrile convulsions: a national cohort study
}

\author{
C M Verity, Jean Golding
}

\section{Abstract}

Objective-To identify children with febrile convulsions, classify their febrile convulsions into simple and complex, and determine the number and type of subsequent afebrile seizures in those children.

Design - National population based study.

Setting-United Kingdom.

Subjects-16004 neonatal survivors born during one week in April 1970.

Main outcome measures-Information about febrile and afebrile seizures obtained from questionnaires at 5 and 10 years of age and from hospital records.

Results-Information was available for 14676 of the cohort children. $398(2.7 \%)$ of them had had at least one febrile convulsion. 16 children were known to be neurologically or developmentally abnormal before the first attack. Of the remaining $\mathbf{3 8 2}$ children, 305 had had a simple first febrile convulsion and 77 a complex first febrile convulsion. Thirteen of the $\mathbf{3 8 2}$ had had one or more afebrile seizures, nine of whom had developed epilepsy (recurrent afebrile seizures). A higher proportion of children with complex febrile convulsions $(6 / 95)$ rather than simple febrile convulsions (3/287) developed epilepsy, the risk being highest for those who had had focal febrile convulsions $\left(5 / 17 ; \chi^{2}=39.9, p<0.001\right)$. Three of the 32 children who had prolonged febrile convulsions developed afebrile complex partial seizures

Conclusions - The risk of epilepsy after febrile convulsions is much less than reported in many

\section{Definitions of convulsions}

Febrile convulsion-An event in infancy or childhood associated with fever but without evidence of intracranial infection or defined cause. This is similar to the National Institutes of Health definition. Children with previous afebrile seizures were excluded. Suspected seizures in the first four weeks of life were excluded but convulsions during vaccination fevers were included.

Department of Paediatrics, Addenbrooke's Hospital, Cambridge CB2 2QQ

C M Verity, FRCP, consultant paediatric neurologist

Institute of Child Health, University of Bristol, Bristol

Jean Golding, PHD, professor

Correspondence to: $\mathrm{Dr}$ Verity.

BMf 1991;303:1373-6

Complex febrile convulsion-Longer than 15 minutes, focal, or multiple (more than one convulsion per episode of fever).

\section{Simple febrile convulsion-Not complex.}

Recurrent febrile convulsion-More than one episode of fever associated with convulsions.

Afebrile convulsion-Classification based on proposals of the International League Against Epilepsy. Children with more than one afebrile attack defined as having epilepsy. hospital studies, and if febrile convulsions cause brain damage that leads to later epilepsy this is a rare occurrence.

\section{Introduction}

Hospital based studies have reported a high incidence of epilepsy in children after febrile convulsions - up to $40 \% .^{\prime}$ In contrast, population based studies suggest that the outcome is better, with incidences of $2 \%$ and $3.5 \%$ in two large American studies. ${ }^{23}$ Febrile convulsions may cause later afebrile seizures or some children may be predisposed to both febrile convulsions and subsequent afebrile seizures.

The child health and education study, ${ }^{45}$ which began as the British births survey, ${ }^{6}$ is one of the few cohort studies large enough to study outcome after febrile convulsions without the bias inherent in hospital based studies. We report the risk of afebrile seizures and epilepsy after febrile convulsions using data obtained when the cohort of children were aged 10 .

\section{Subjects and methods}

The British birth survey enrolled 16004 neonatal survivors $-98.5 \%$ of the infants born in the United Kingdom in one week in April 1970. Of these children, $13135(82 \%)$ were assessed at 5 years of age and 14902 $(93 \%)$ at 10 years. At the assessments parents were asked: "Has the child ever had any form of convulsion, fit, seizure or other turn in which consciousness was lost or any part of the body made an abnormal movement?" After the 10 years assessment replies to this question were available for 14676 children, of whom 1318 were judged to have had a suspicious event. Reported suspicious events were validated by sending questionnaires to general practitioners and by obtaining hospital records. Questionnaires were returned for $1212(92 \%)$ children and records obtained for $1173(89 \%)$. Children with confirmed febrile convulsions were classified according to the type of convulsion (box). Comparisons between groups were analysed by the $\chi^{2}$ test with Yates's correction.

\section{Results}

AGE OF ONSET, INCIDENCE, AND RECURRENCE OF FEBRILE CONVULSIONS

Of the 1318 children who had had suspicious events, of age (median (range) age of onset 1 year 7 months ( 2 months -7 years 9 months)). The remaining children had had other attacks such as breath holding attacks and afebrile seizures and will be discussed elsewhere. Two children who had had seizures and 398 had had at least one febrile convulsion by 10 years 
fever had been diagnosed as having encephalitis. They were not included in the febrile convulsion group.

Sixteen of the 398 children who had febrile convulsions were known to be neurologically or developmentally abnormal before their first febrile convulsion. In 10 of the 16 the first febrile convulsion had been complex, and four had developed afebrile tonic-clonic seizures. These 16 were excluded for the rest of the analyses except where specifically stated.

The remaining 382 children were subdivided into those who had had simple febrile convulsions and those who had had complex febrile convulsions. This classification was done, firstly, on the basis of the first febrile convulsion and, secondly, on the basis of ever having had a complex febrile convulsion. In all, 305 of the children had a simple first febrile convulsion, of whom 18 later had a complex febrile convulsion. Significantly more of the children whose first febrile convulsion had been complex rather than simple had a febrile recurrence (37/77 (48\%) complex $v$ 105/305 $(34 \%)$ simple; $\left.\chi^{2}=4 \cdot 3, p<0.05\right)$. Similarly, more of the children who had ever had complex febrile convulsions had a febrile recurrence $(55 / 95(58 \%)$ complex $v 87 / 287$ $(30 \%)$ only simple; $\left.\chi^{2}=22 \cdot 1, \mathrm{p}<0 \cdot 001\right)$.

\section{CLINICAL DETAILS}

Among the 382 children who had had febrile convulsions, $78 \%(74 / 95)$ of those who had ever had complex convulsions were admitted to hospital compared with $58 \%(168 / 287)$ of those who had only had simple convulsions $\left(\chi^{2}=10 \cdot 7, p<0.01\right)$.

Data about anticonvulsant drugs were available for 293 children (217/287 simple seizures, 76/95 complex seizures). Forty children ( 26 simple, 14 complex) were prescribed prophylactic anticonvulsants for longer than a month. None of the children with febrile convulsions died.

\section{OUTCOME AFTER FEBRILE CONVULSIONS}

Thirteen of the 382 children had had one or more afebrile seizures. Six had had tonic-clonic seizures, six complex partial seizures, and one a mixed seizure disorder. Nine of the 13 had had more than one afebrile seizure - that is, had developed epilepsy. The median age of onset of afebrile seizures in the 13 children was 5 years 1 month. The median interval between the first febrile convulsion and the first afebrile seizure was 3 years 10 months.

Of the 13 children, nine had had complex febrile convulsions and six of them had had later afebrile complex partial seizures. All five children who had had complex febrile convulsions with focal features later developed afebrile complex partial seizures. The four children who had only simple febrile convulsions developed afebrile tonic-clonic seizures.

Three of the 32 children who had prolonged febrile convulsions later had one or more afebrile complex partial seizures; in two of them the prolonged febrile convulsions occurred in the first year of life and also had focal features.

Four $(5 \%)$ of the 81 children who had had their first febrile convulsions aged less than 1 year later had afebrile seizures and three (4\%) developed epilepsy, not significantly different from the nine (3\%) who had afebrile seizures and six (2\%) who developed epilepsy among the 301 who had had febrile convulsions when older than 12 months.

Significantly more children who had had recurrent rather than single febrile convulsions had afebrile seizures $(9 / 142(6 \%)$ with recurrences $v 4 / 240(2 \%)$ single; $\left.\chi^{2}=4.6, p<0.05\right)$. This was difficult to evaluate in isolation, however, as recurrent febrile convulsions were more common in children who had had complex febrile convulsions than in those who had had simple febrile convulsions.
Among children for whom information on family history of epilepsy in first degree relatives was available significantly more children with a family history had later afebrile seizures than children with no family history $(3 / 19(16 \%)$ with history $v 9 / 274(3 \%)$ no history; $\left.\chi^{2}=4 \cdot 3, p<0.05\right)$. Again this was difficult to evaluate in isolation because significantly more children who had had complex rather than simple febrile convulsions had a family history $(11 / 82(13 \%)$ complex $v 8 / 211(4 \%)$ simple; $\left.\chi^{2}=7 \cdot 5, \mathrm{p}<0 \cdot 01\right)$.

\section{RISK OF EPILEPSY}

Table I shows the percentage of children who developed epilepsy after simple and complex febrile convulsions. A greater proportion of the children who had a complex first febrile convulsion developed epilepsy than the proportion who had a simple first febrile convulsion, but this did not reach significance. Outcome differed according to individual complex features, in particular first febrile convulsions that had focal features were significantly more likely to be followed by epilepsy $\left(\chi^{2}=15 \cdot 4, p<0.001\right)$.

When children were classified on the basis of ever having had a complex febrile convulsion the results were similar to those above. When compared with those who had only had simple febrile convulsions a significantly greater proportion of those who had ever had complex febrile convulsions $\left(\chi^{2}=6.5, p<0.05\right)$ and of those who had ever had focal febrile convulsions $\left(\chi^{2}=39 \cdot 9, \mathrm{p}<0.001\right)$ developed epilepsy.

\section{CHILDREN WITHOUT FEBRILE CONVULSIONS}

There were 14278 children in our study who had no febrile convulsions, and $53(0 \cdot 4 \%)$ of them developed epilepsy by the age of 10 years. This is lower than the proportions who developed epilepsy in the children who had simple or complex febrile convulsions (table I). Table II shows the number of children who had had afebrile tonic-clonic and complex partia seizures. We used the data on children who did not have febrile convulsions to calculate the expected number of children with afebrile seizures in the 398 children who had had febrile convulsions. The observed number in the febrile convulsion group was 10 times

TABLE I-Afebrile seizures and epilepsy in children who had febril convulsions

\begin{tabular}{|c|c|c|c|}
\hline Febrile convulsion & $\begin{array}{l}\text { No of } \\
\text { children }\end{array}$ & $\begin{array}{l}\text { No }(\%) \text { who had } \\
\text { one or more } \\
\text { afebrile seizure }\end{array}$ & $\begin{array}{c}\text { No (\%) who had } \\
\text { epilepsy }\end{array}$ \\
\hline \multicolumn{4}{|c|}{ First febrile convulsion } \\
\hline Simple & 305 & $8(3)$ & $5(2)$ \\
\hline Complex $†$ & 77 & $5(6)$ & $4(5)$ \\
\hline Multiple & 42 & $1(2)$ & $1(2)$ \\
\hline Prolonged & 30 & $3(10)$ & $2(7)$ \\
\hline Focal & 13 & $3(23)^{\star \star}$ & $3(23)^{\star \star \star}$ \\
\hline \multicolumn{4}{|c|}{ Any febrile convulsion } \\
\hline Simple & 287 & $4(1)$ & $3(1)$ \\
\hline Complex $\dagger$ & 95 & $9(9)^{\star \star \star}$ & $6(6)^{\star}$ \\
\hline Multiple & 55 & $3(5)$ & $2(4)$ \\
\hline Prolonged & 32 & $4(13)^{\star \star}$ & $2(6)$ \\
\hline Focal & 17 & $5(29)^{\star \star \star}$ & $5(29)^{\star \star \star}$ \\
\hline
\end{tabular}

${ }^{\star} \mathrm{p}<0.05,{ }^{\star \star} \mathrm{p}<0.01,{ }^{\star \star \star} \mathrm{p}<0.001$ compared with children who had simple febrile convulsions.

tSome children had convulsions with more than one complex feature.

TABLE II-Comparison of number of children who had afebrile seizures among those who had febrile seizures and those who had not

\begin{tabular}{lcc}
\hline & $\begin{array}{c}\text { No of children } \\
\text { with tonic-clonic } \\
\text { seizures }\end{array}$ & $\begin{array}{c}\text { No of children with } \\
\text { complex partial } \\
\text { seizures }\end{array}$ \\
\hline $\begin{array}{c}\text { Children who had not had febrile } \\
\text { convulsions }(\mathbf{n}=14278)\end{array}$ & 36 & 19 \\
$\begin{array}{c}\text { Observed in children who had } \\
\text { febrile convulsions }(\mathrm{n}=398)\end{array}$ & 10 & 6 \\
$\begin{array}{c}\text { Expected in children who had } \\
\text { febrile convulsions }\end{array}$ & 1 & 0.5 \\
\begin{tabular}{l} 
Observed/expected \\
\hline
\end{tabular} & 10 & 12
\end{tabular}

^Based on findings in children who had no febrile convulsions. 
that expected for tonic-clonic seizures and 12 times that expected for complex partial seizures, but the ratio of the two types of afebrile seizures was almost the same as in children who did not have febrile convulsions.

\section{Discussion}

It is difficult to compare our study with others because of differences in design and in definitions of epilepsy. For instance, Wallace defined a febrile convulsion as "any convulsion occurring in association with any febrile illness." Our definition excluded children with "evidence of intracranial infection or defined cause," as did that used by Nelson and Ellenberg ${ }^{2}$ and Annegers $\mathrm{et} \mathrm{al}^{3}$

Hospital based studies tend to select those children with more severe attacks. ${ }^{1}$ Wallace reported that $62 \%$ of children admitted to hospital for febrile convulsions had a "complicated" initial attack, ${ }^{9}$ whereas only $20 \%$ had a complex first attack in our study and $18 \%$ in an American population based study. ${ }^{2}$ The 1958 British cohort study found that children admitted to hospital with febrile convulsions were more likely to develop afebrile seizures, ${ }^{10}$ again suggesting that the more severe attacks lead to hospital admission.

It has been reported that the younger children are at the onset of febrile convulsions, the more likely they are to develop epilepsy, particularly if the febrile convulsions occur in the first year of life. ${ }^{1}$ We found no evidence to support this, perhaps because numbers were too small.

Although there are differences in study design the conclusions reached by the large population based studies are similar to ours. The incidence of febrile convulsions in our study $(2 \cdot 7 \%)$ is comparable with the $2.4 \%$ found in children up to the age of 11 in the national child development study. ${ }^{10}$ The proportions of children with febrile convulsions that had multiple, prolonged, or focal features are almost identical with those in the American national collaborative perinatal project. ${ }^{2}$ Our incidences of afebrile seizures after febrile convulsions at 10 years of age are slightly higher than those reported at 7 years of age by Nelson and Ellenberg (2.5\% had epilepsy at age $10 v 2.0 \%$ at age 7). ${ }^{2}$ This agrees with the report from Annegers et al that the cumulative risk of an unprovoked seizure increases with age. ${ }^{11}$

\section{FACTORS ASSOCIATED WITH AFEBRILE SEIZURES}

In children who had had febrile convulsions both recurrent febrile convulsions and a family history of epilepsy were apparently related to later afebrile seizures; but we could not properly evalute either factor because both were associated with the occurrence of complex febrile convulsions. Annegers et al analysed the influence of these factors on a multivariate basis and found that after febrile convulsions the occurrence of unprovoked seizures of generalised (but not partial) onset was associated with the number of preceding febrile convulsions and with a family history of "unprovoked" seizures."

We found that a significantly greater proportion of the children who had ever had complex (rather than simple) febrile convulsions developed epilepsy. Also the outcome differed among the three individual complex features (multiple, prolonged, or focal), in particular a significantly greater proportion of children with focal febrile convulsions developed epilepsy. Similar results were found by Nelson and Ellenberg using univariate analysis ${ }^{2}$ and by Annegers et al, who used both univariate and multivariate analysis and found that the three complex features of febrile convulsions were independent predictors of later afebrile seizures. ${ }^{\prime \prime}$
FEBRILE CONVULSIONS AND BRAIN DAMAGE

Animal experiments show that prolonged seizures can lead to localised cerebral damage. ${ }^{12}$ Evidence that prolonged febrile convulsions cause damage leading to epilepsy has come retrospectively from the study of adults with intractable complex partial seizures (temporal lobe epilepsy) many of whom had a history of prolonged febrile convulsions. ${ }^{1314}$ In 1977 Wallace reported an association between convulsions with fever that were severe and unilateral and later "psychomotor epilepsy," concluding that prevention of epilepsy lies in preventing prolonged fits. ${ }^{15}$ It has also been suggested that the occurrence of a convulsion makes it easier for another seizure to occur. ${ }^{16}$ We found little evidence that there was progressive "damage" leading to more severe attacks: after a first simple febrile convulsion the proportion of febrile recurrences that were complex was $17 \%(18 / 105)$, less than the $20 \%(77 / 305)$ of first febrile convulsions that were complex. Also only four children had a first simple febrile convulsion followed by a complex febrile recurrence and then by afebrile seizure.

As for the question of prolonged febrile convulsions causing later epilepsy, 32 of the 398 children with febrile convulsions had prolonged convulsions. Three of these children, two of whose convulsions also had focal features, later had complex partial seizures. A fourth child had one afebrile tonic-clonic seizure. Although we found an association between the occurrence of focal febrile convulsions and later complex partial seizures, the ratio between afebrile tonic-clonic seizures and complex partial seizures in children who had had febrile convulsions was almost the same as that in children who had never had febrile convulsions. Annegers $e t a l^{11}$ and Lee $e t a l^{17}$ reported similar results. These findings are compatible with the hypothesis that febrile convulsions do not contribute appreciably to the occurrence of partial complex seizures. ${ }^{18}$ The tendency to have complex febrile convulsions may reflect pre-existing brain disease that is also responsible for the subsequent development of partial epilepsy, ${ }^{11}{ }^{19}$ and our data support that suggestion.

\section{ROLE OF ANTICONVULSANTS}

Although our study was not designed to evaluate the role of anticonvulsants in preventing afebrile seizures after febrile convulsions some conclusions can be drawn. Only a small proportion of the children were prescribed anticonvulsants for more than a month as prophylaxis against febrile convulsions, so it seems unlikely that anticonvulsant drugs had much influence on outcome in our study. As only four of the 287 children who had had only simple febrile convulsions later had afebrile seizures, there seems little support for prescribing anticonvulsants in this case. Children with complex febrile convulsions were more likely to develop afebrile seizures but even so only nine of the 95 who had ever had complex febrile convulsions developed afebrile seizures. Five of the nine had had complex first febrile convulsions so any damage caused by a complex convulsion would have been sustained before prophylactic medication could be considered.

We conclude that there is only a small risk of developing afebrile seizures after most febrile convulsions and that prophylactic anticonvulsants are unlikely to reduce the risk significantly.

Professor Neville Butler created the child health and education study from the original birth week studies. The study was funded by the Medical Research Council, the Department of Health and Social Security, and the Gertrude H Sergievsky Center, Columbia University, New York. We thank the midwives, health visitors, general practitioners, medical records officers, and clinicians who provided the essential information, and the children and their parents. 
Wallace SJ. The child with febrile seizures. London: John Wright, 1988:109-26. Nelson KB, Ellenberg JH. Predictors of epilepsy in children who have experienced febrile seizures. $N$ Engl f Med 1976;295:1029-33.

3 Annegers JF, Hauser WA, Elveback LR, Kurland LT. The risk of epilepsy following febrile convulsions. Neurology 1979;29:297-303.

+ Verity CM. Butler NR, Golding J. Febrile convulsions in a national cohort followed up from birth. I. Prevalence and recurrence in the first five years of life. $B M 7$ 1985;290:1307-10

5 Verity CM, Butler NR, Golding J. Febrile convulsions in a national cohort followed up from birth. II. Medical history and intellectual ability at 5 years of age. BMY 1985;290:1311-5.

6 Chamberlain R, Chamberlain G, Howlett B, Claireaux A. British births 1970. Vol 1. The first week of life. London: William Heinemann, 1975.

7 National Institutes of Health. Febrile seizures: long term management of children with fever-associated seizures. Summary of an NIH consensus statement. $B M \mathcal{1}$ 1980;281:277-9.

8 Commission on Classification and Terminology of the International League Against Epilepsy. Proposal for revised clinical and electroencephalographic classification of epileptic seizures. Epilepsia 1981;22:489-501.

9 Wallace SJ. Factors predisposing to a complicated initial febrile convulsion. Arch Dis Child 1975:50:943-7.

10 Ross EM, Peckham CS, West PB, Butler NR. Epilepsy in childhood: findings from the national child development study. BMF 1980;280:207-10.

11 Annegers JF, Hauser WA, Shirts SB, Kurland LT. Factors prognostic of unprow.

(1987;316:

Secondary pathology of febrile and experimental convulsion In: Brazier MAB, Coceani $\mathrm{F}$, eds. Brain dysfunction in infantile febrile convulsions. New York: Raven, 1976:213-22.

13 Falconer MA, Serafetinides EA, Corsellis JAN. Etiology and pathogenesis of temporal lobe epilepsy. Arch Neurol 1964;10:233-48.

14 Taylor DC, Ounsted C. Biological mechanisms influencing the outcome of seizures in response to fever. Epilepsia 1971;12:33-45.

15 Wallace SJ. Spontaneous fits after convulsions with fever. Arch Dis Child 1977;52:192-6.

16 Reynolds EH. Early treatment and the prognosis of epilepsy. Epilepsia 1987;28:97-106

17 Lee K, Diaz M, Melchior JC. 'Temporal lobe epilepsy - not a consequence of childhood febrile convulsions in Denmark. Acta Neurol Scand 1981;63: 231-6.

18 Leviton A, Cowan LD. Do febrile seizures increase the risk of complex partial seizures? An epidemiologic assessment. In: Nelson KB, Ellenberg JH, eds. Febrile seizures. New York: Raven, 1981:65-74.

19 Rocca WA, Sharbrough FW, Hauser WA, Annegers JF, Schoenberg BS. Risk factors for generalized tonic-clonic seizures: a population-based case-control study in Rochester, Minnesota. Neurology 1987;37:1315-22.

(Accepted 25 September 1991)

\section{Severe cystitis associated with tiaprofenic acid}

\section{Ahmed, O W Davison}

\section{Kettering General Hospital, \\ Northamptonshire \\ NN16 8UZ \\ M Ahmed, FRCS, registrar in urology \\ O W Davison, FRCS, \\ consultant urologist}

Correspondence to: Mr Ahmed, 128 Knight's

Manor Way, Dartford, Kent DA1 5SP.

BMF 1991;303:1376
Cystitis, or inflammation of bladder mucosa, presents as urinary frequency, nocturia, and dysuria. Most cases of cystitis are infective, though local chemical inflammation may be responsible in some cases. We report three cases of severe cystitis associated with tiaprofenic acid.

\section{Case reports}

CASE 1

An 82 year old woman was prescribed triaprofenic acid $300 \mathrm{mg}$ twice a day in December 1987 for osteoarthritis. She was also taking bendrofluazide $5 \mathrm{mg}$ once a day. No previous allergy or intolerances were known. Within weeks of starting treatment with tiaprofenic acid she developed symptoms of urinary frequency, dysuria, and nocturia with a sterile pyuria and microscopic haematuria. She was given multiple antibiotics and topical oestrogens but none resolved the symptoms.

An intravenous urogram and urine cytology appeared normal and a urinary culture was negative for mycobacterium. Cystoscopy showed severe global cystitis. Histological examination of multiple bladder biopsy specimens showed that most of the bladder mucosa was replaced by inflammatory cell infiltrate in the submucosa, suggestive of interstitial cystitis. Tiaprofenic acid was discontinued and within two weeks her urinary symptoms had completely resolved. Cystoscopy six weeks later showed complete resolution of cystitis.

\section{CASE 2}

An 81 year old woman was prescribed sustained action tiaprofenic acid in October 1988. She had taken $2.5 \mathrm{mg}$ prednisolone once a day since 1973 for polyarthritis. Within a few weeks of starting tiaprofenic acid she developed cystitis with sterile pyuria. An intravenous urogram showed a partial duplex system on the left side. Analysis of blood chemistry and urine cytology gave normal results and a urine culture was negative for acid fast bacilli. Cystoscopy showed severe generalised cystitis. Four quadrant biopsy specimens showed oedematous stroma with diffuse infiltration of chronic inflammatory cells. The urothelium was completely lost, and special staining showed numerous mast cells, which suggested interstitial cystitis. Cystitis completely resolved on stopping tiaprofenic acid. CASE 3

A 69 year old woman was referred for urological consultation with a six month history of resistant cystitis. She had been taking sustained action tiaprofenic acid $300 \mathrm{mg} /$ day for the past eight months. She was also receiving beclomethasone and salbutamol by inhaler, slow release theophylline $400 \mathrm{mg} / \mathrm{day}$, and bendrofluazide $2.5 \mathrm{mg} /$ day. An intravenous urogram appeared normal. Cystoscopy showed generalised cystitis. Tiaprofenic acid was stopped and a repeat cystoscopy three weeks later confirmed that the cystitis had resolved. She remained free of bladder symptoms one year later.

\section{Comment}

Cystitis as a side effect of systemically administered drugs is rare. A Medline search from 1980 to 1990 yielded 12 reports, most of which related to cyclophosphamide. Other drugs implicated were danazol, which causes haemorrhagic cystitis in patients with hereditary angioneurotic oedema, ${ }^{1}$ and tranilast, an antiallergic drug, which causes eosinophilic cystitis'; one case of cystitis with kanamycin is reported in Russian. Nineteen cases of cystitis with tiaprofenic acid are registered with the Committee on Safety of Medicines.

Tiaprofenic acid is a non-steroidal anti-inflammatory drug of the propionic acid group. It is a potent inhibitor of prostaglandin biosynthesis through inhibition of cyclo-oxygenase. ${ }^{3}$ Tiaprofenic acid is metabolised in the liver, where about $5 \%$ is oxidised to phenol and alcohol derivatives. The parent compound and these metabolites are excreted in urine largely as acylglucuronides. The half life of the drug is short, and steady state is reached on the first day of the treatment.

The mechanism of tiaprofenic acid induced cystitis remains unknown. But awareness of this side effect is important as non-steroidal anti-inflammatory drugs are the most commonly prescribed drugs. In addition tiaprofenic acid induced cystitis could be confused with interstitial cystitis, the treatment of which is highly unsatisfactory and invasive.

\footnotetext{
1 Andriole GL, Brickman C, Lack EE, Sesterhenn IA, Javadpour N, Frank MM, al. Danazol induced cystitis: an undescribed source of hematuria in patients with hereditary angioneurotic edema. F Urol 1986;135:44-6.

2 Navada T, Ishikawa S, Sakamola M, Kalayama T, Iyarashi T, Fukuda T, et al. $\mathrm{N}-\left(3^{\prime}, 4^{\prime}\right.$-dimethoxicinnamovl) anthranillic acid, an antiallergic compound, induced eosinophilic cystitis. Urol Int 1986:41:457-64.

3 Sorkin EM, Brogden RN. Tiaprofenic acid. A review of its pharmacologica properties and therapeutic efficacy in rheumatic diseases and pain states. Drugs 1985;29:208-35.
}

Accepted 17 September 1991 